\title{
Students distracted by electronic devices perform at the same level as those who are focused on the lecture
}

Background: Little is known about the characteristics of internet distractions that students may engage in during lecture and the objective of this pilot study is to identify some of the internet based distractions students engage in during in-person lectures. The findings of this pilot study will help to identify what activities most commonly cause students to be distracted from the lecture and if these activities impact student learning. Methods: This study is a quasi-experimental pilot study of 26 students from a single institution. In the current study, one class of third year students were surveyed after a lecture on special needs dentistry. The survey identified self reported utilization patterns of "smart" devices during the lecture. Additionally, twelve quiz-type questions were given to assess the students' recall of the important points of the lecture material that had just been covered. Results: The sample comprised of 26 students. Of these, 17 were distracted in some form (either checking email, sending email, checking face book, or sending texts). The overall mean score on the test was 9.85 (9.53 for distracted students and 10.44 for non-distracted students). There were no significant differences in test scores between distracted and non-distracted students $(p=0.652)$. Gender and types of distractions were not significantly associated with test scores ( $p>0.05$ ). All students believed that they understood all the important points from the lecture Conclusions: Every class member felt that they acquired the important learning points during the lecture. Those who were distracted by electronic devices during the lecture performed similarly to those who were not. However, results should be interpreted with caution as this study was a small quasi-experimental design and further research should examine the influence of different types of distraction on different types of learning. 
1 Students distracted by electronic devices perform at the same level as those who are focused

2 on the lecture

3 Romesh P. Nalliah BDS ${ }^{1}$, Veerasathpurush Allareddy BDS MBA MHS MMSc PhD²

4 1- Instructor, Department of Global Health, Harvard School of Dental Medicine, Boston, 5 MA, 02115

6 2- Associate Professor, Department of Orthodontics, College of Dentistry - The University $7 \quad$ of Iowa, Iowa City, IA 52242.

8 Key words: Flipped class room, learning methods, dental education

9 Please address correspondence and reprint requests to

10 Veerasathpurush Allareddy

11 Department of Orthodontics

12 University of Iowa - College of Dentistry

13 Email: Veerasathpurush-Allareddy@uiowa.edu

14 Telephone: 319-353-5806 


\section{ABSTRACT}

16 Background: Little is known about the characteristics of internet distractions that students may

17 engage in during lecture and the objective of this pilot study is to identify some of the internet

18 based distractions students engage in during in-person lectures. The findings of this pilot study

19 will help to identify what activities most commonly cause students to be distracted from the

20 lecture and if these activities impact student learning.

21 Methods: This study is a quasi-experimental pilot study of 26 students from a single institution.

22 In the current study, one class of third year students were surveyed after a lecture on special

23 needs dentistry. The survey identified self reported utilization patterns of "smart" devices during

24 the lecture. Additionally, twelve quiz-type questions were given to assess the students' recall of

25 the important points of the lecture material that had just been covered.

26 Results: The sample comprised of 26 students. Of these, 17 were distracted in some form (either

27 checking email, sending email, checking face book, or sending texts). The overall mean score on

28 the test was 9.85 (9.53 for distracted students and 10.44 for non-distracted students). There were

29 no significant differences in test scores between distracted and non-distracted students $(\mathrm{p}=0.652)$.

30 Gender and types of distractions were not significantly associated with test scores $(p>0.05)$. All

31 students believed that they understood all the important points from the lecture

32 Conclusions: Every class member felt that they acquired the important learning points during the

33 lecture. Those who were distracted by electronic devices during the lecture performed similarly to

34 those who were not. However, results should be interpreted with caution as this study was a small

35 quasi-experimental design and further research should examine the influence of different types of 36 distraction on different types of learning. 


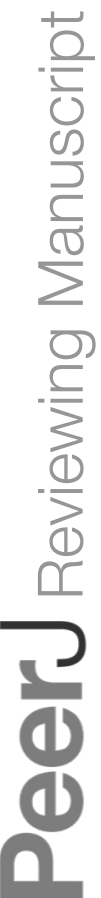

PeerJ reviewing PDF | (v2014:02:1507:2:0:NEW 18 Aug 2014) 


\section{INTRODUCTION}

38 Most students currently enrolled in dental schools in the United States (US) were born in

39 the 1980's or 1990's (Pew Internet and American Life Project, 2010; Elam, Stratton \& Gibson,

40 2007). This generation is referred to as Generation $\mathrm{Y}(\mathrm{Gen} \mathrm{Y})$ and they function very differently

41 to previous generations of dental students. Research in dental hygiene education has shown that

42 Gen Y students revel in group work and are sagacious technology users (Blue, 2009).

43 Previous research has shown that passively listening to lectures is less effective than being

44 engaged in a lecture where the student must solve "retrieval" questions that require them to go

45 back to the information and find the answers (Karpicke \& Blunt, 2011). The flipped classroom

46 model is based on this concept and retrieval questions and discussions are during the classroom

47 session. Gen Y students also have a proclivity to multitask and a need for immediate feedback

48 which the retrieval questions would provide (Blue, 2009). It is not currently known if

49 multitasking during lectures impacts learning outcomes. Lectures are designed to be uni-tasking

50 experiences that require the student to be fully engaged in the verbal and (sometimes) visual

51 dissemination of information. Traditional lectures do not support multitasking activities, and, may

52 actually be in conflict with them.

53 A recent study on the impact of lecture retention from fidgeting and mind wandering

54 showed that retention of lecture material declined as time spent on a task increased. Additionally,

55 fidgeting also increased as time increased and fidgeting had a negative impact on retention

56 (Farley, Risko \& Kingstone, 2013). This suggests that shorter time span educational activities

57 may be more effective for retention. This paper reports the outcomes of a small quasi-

58 experimental pilot study that assessed the role of distraction versus not in learning outcomes of a

59 single lecture at Harvard School of Dental Medicine (HSDM). The post-lecture test was designed

60 to measure content retention from the lecture and the post-lecture survey is designed to determine

61 what electronic activities like texting and emailing students were engaged in. The objective of the 
62 paper is to compare retention outcomes to level of engagement in electronic activities. Although

63 engaging in electronic activities doesn't necessarily mean the student was distracted, we have

64 compared whether or not students engaged in these activities to their performance on a content 65 retention test. 


\section{MATERIALS AND METHODS}

67 Study Design: The current study is a pilot cross-sectional study at Harvard School of Dental

68 Medicine. A traditional lecture (on special needs dentistry) was delivered and a post-lecture

69 questionnaire was administered to a $3^{\text {rd }}$ year class at HSDM. After the traditional lecture, a post-

70 lecture test was administered which included 12 multiple choice test questions relating to the

71 lecture content to evaluate how effectively students learned the information in the lecture. The

72 post-lecture test measured understanding and knowledge of the important concepts from the

73 lecture. The post-lecture survey (this was not anonymous) also asked several questions about

74 what electronic activities students were engaged in during the lecture. Harvard Medical School

75 Institutional Review Board exemption was acquired for this study. The protocol number is

76 IRB13-1300.

77 Analytical Approach: Simple descriptive statistics were used to summarize the data. The primary

78 outcome variable was the test scores (computed on a scale of 0 to 12). There were 12 multiple

79 choice questions and each question was assigned one point. The primary independent variables of

80 interest were if the students were distracted, type of distraction, and gender. The distribution of

81 test scores was compared between distracted and non-distracted students using Man Whitney U

82 tests. Two multivariable linear regression models were used to examine the simultaneous

83 influence of gender and distraction on test scores. In the first model, a composite variable

84 (whether the student was distracted by any form) for distraction and gender were used as

85 independent variables. In the second model, the different types of distractions (checking email,

86 sending email, checking face book, or sending text) were used separately along with gender. In

87 both models, the test scores was the outcome variable. Both regression models were fit using the

88 Ordinary Least Squares approach. All tests were two sided and a p-value of $<0.05$ was deemed to

89 be statistically significant. All statistical analyses were conducted using SPSS Version 22.0

90 software (IBM Corp, Research Triangle Park, NC). 


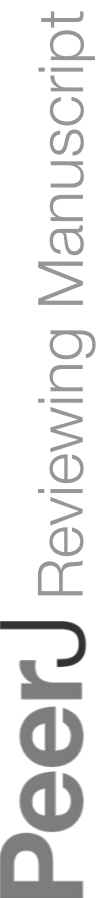

PeerJ reviewing PDF | (v2014:02:1507:2:0:NEW 18 Aug 2014) 


\section{RESULTS}

92 There were 27 students who participated in this lecture. One student did not complete the

93 test or survey and was was omitted from the evaluation leaving a final sample of 26 students. The

94 final sample comprised of 8 males and 18 females.

95 During the lecture, $57.7 \%$ reported that they checked their email and $11.5 \%$ reported

96 sending an email, $15.4 \%$ checked Facebook, and $7.7 \%$ sent a text message. Of those who checked

97 their email $69 \%$ used their smart phone, $18 \%$ used their laptop and $13 \%$ used an iPad. Seventeen

98 of the 26 students $(65.4 \%)$ were distracted in some form during the lecture.

99 There were 12 post-lecture multiple choice questions related to the lecture materials and

100 the proportion of the class that got each question correct is listed: Q1, 73\%; Q2, 65\%; Q3, 69\%;

101 Q4, 96\%; Q5, 81\%; Q6, 81\%; Q7, 85\%; Q8, 92\%; Q9, 96\%; Q10, 58\%; Q11, 88\%; Q12, 100\%.

102 On a scale of 0 to 12 (with 1 point for each question), the mean score for the class was 9.85

103 (standard deviation is 2.89). The distribution of test scores are summarized in table 1. The mean

104 score amongst those that were distracted was 9.53 (compared to 10.44 for students that were not

105 distracted. Overall, there was no significant difference in distribution of test scores between

106 students that were distracted and not distracted (p-value from Man Whitney U test is 0.652 ). In

107 the survey, $100 \%$ of students believed that they understood all the important points from the 108 lecture.

109 Results of the multivariable linear regression analysis examining the simultaneous

110 association of gender and distraction on test scores are summarized in table 2. After adjustment

111 for the effects of distraction, males were associated with 2.6 points higher scores compared to

112 females. However, this was not statistically significant $(\mathrm{p}=0.052)$. After adjustment for the effects

113 of gender, those who were distracted did not have a significantly different score when compared 
114 to those who were not distracted $(\mathrm{p}=0.955)$. Gender and distraction explained $17.5 \%$ of variance 115 in test scores.

116 Results of the multivariable linear regression examining the effects of different types of

117 distractions and gender on test scores are summarized in table 3. Overall, there were no

118 statistically significant differences in test scores for the different types of distractions: checking 119 email (estimate is $-0.88, \mathrm{p}=0.476$ ), sending email (estimate is $2.40, \mathrm{p}=0.166$ ), checking face book

120 (estimate is $-2.16, \mathrm{p}=0.293$ ), or sending text (estimate is $3.66, \mathrm{p}=0.199$ ) after adjusting for the

121 effects of gender (estimate is $2.44, \mathrm{p}=0.007$ ). In this model, gender and different types of

122 distractions explained $32 \%$ of variance in test scores. 


\section{DISCUSSION}

124 Lecture theaters used to be the only source of information but the direction education is

125 moving is readily available information that is convenient and accessible at all times through

126 electronic resources. Current generations of students are thought to require more engaged

127 teaching modalities (Massachusetts Institute of Technology, 2014). In fact, a Pew report found

128 that $87 \%$ of teachers believed modern technology was creating an easily distracted generation of

129 students with short attention spans (Pew-a, 2014). Another Pew study showed that 24\% of Gen Y

130 report that technology use is what makes their generation unique (Pew-b, 2014). However, little

131 is known about the impact on learning of being engaged in electronic activities during lecture.

132 This paper reports outcomes of a small study that was designed to evaluate the learning outcomes

133 of a traditional lecture among Gen Y students.

134 In the current study, students attended a traditional lecture and were given a post-test

135 about the lecture topic and a questionnaire. The questionnaire asked the students whether they

136 checked/sent email, checked Facebook accounts or sent text messages during the lecture.

137 Certainly, there is a possibility that students were not completely honest with their answers and

138 our findings may be an underrepresentation of the actual amount of involvement with electronic

139 devices and the internet that was unrelated to the lecture. We found that $57.7 \%$ of students

140 checked their email; $11.5 \%$ sent an email; $15.4 \%$ checked their face book account and $7.7 \%$ sent

141 a text message during the lecture. Remarkably, the "distracted" group (those that engaged in one

142 of these activities during the lecture) performed similarly in the post-test to the undistracted

143 group.

144 A total of $65.4 \%$ of the class reported engaging in "distracting" behavior such as emailing, using

145 Facebook or texting. Nonetheless, $100 \%$ of the students believed that they had understood the

146 important concepts discussed in the lecture. However, in some questions, only $58 \%$ of students

147 knew the correct answer. The major concern is that all students believed they understood the 
148 important concepts but there were three questions in the post-test where less than $70 \%$ knew the

149 correct answer. Overall learning outcomes were not ideal, however, the group that reported being

150 distracted performed similarly to the group that said they were not distracted. Existing research

151 concurs with this finding and reports that media multitasking was not related to self-reported

152 difficulties in distractibility (Pew-b, 2014). In the current study, 58.8\% of the "distracted" group

153 and 55.6\% of "non-distracted" answered all questions correctly.

154 Notably, in the current study all males who were engaged in a "distracting" behavior

155 scored $100 \%$ in the post-test. However, among females engaged in "distracting" behaviors and

156 only 50\% got all questions correct. The mean score for males was 11.63 points compared to 9.06

157 in females. However, the overall scores were not statistically significantly different between

158 males and females. The small sample size in the current study could have precluded from

159 identifying a statistically significant difference in test scores between males and females. It

160 should also be noted that non-distracted males also performed better than their female

161 counterparts and there may be some gender bias in our test. Additionally, our pilot study is small

162 and there is insufficient statistical power to demonstrate that men multitask better during dental

163 school lectures, however, it is interesting that males seemed to outperform females when

164 "distracted" during the current study. This finding is in conflict with several articles in the media

165 but concurs with one previous scientific study (Huffington Post, 2014; Live Science, 2014;

166 National Geographic 2014; Mantyla, 2013) ${ }^{14}$ It may be possible that multitasking during a

167 lecture does not significantly affect learning among males but does reduce learning among

168 females. Larger studies are necessary to evaluate this further.

169 It is, however, important to note that the overall mean test score for distracted students

170 was 9.53 (on a scale of 0 to 12), whereas, the mean score for non-distracted students was 10.44 .

171 Measures that reduce distracted behaviors such as blocking wireless internet access in lecture 
172 theaters may aid in maintaining the effectiveness of lectures as a mode of education in the 173 modern era.

174 An interesting study comparing emergency room (ER) doctors to regular ward doctors

175 found that ER doctors switched tasks more frequently. However, ward doctors multi-tasked more

176 frequently than ER doctors (Walter et al 2013). It seemed from the study that safety may be

177 implicit in task-switching and multitasking decisions. In the current study of dental students, we

178 found that multi-tasking didn't necessarily have a negative impact on learning performance as

179 some distracted students (particularly males) were able to score $100 \%$ in the post-test.

180 Since current generations of students are very comfortable with technology and often

181 have their electronic device near them, some thought should be given to the integration of these

182 devices as learning tools for medical and dental students as they transition to independent

183 practice. More research is necessary to evaluate patient perception of electronic device use by

184 doctors and the merits of including appropriate use of electronic devices during education and 185 patient visits.

186 Additionally, caution should be used when embracing new methods of teaching. The

187 current study shows that students who became distracted during a traditional lecture performed

188 similarly to those who were not. Educational outcomes and costs to the institution should be

189 thoroughly considered when implementing curricular changes. Larger studies that compare

190 educational outcomes of traditional lectures to other modalities of teaching will help determine

191 the place of the traditional lecture in modern curricular.

192 It should be noted that this was a small, quasi-experimental, exploratory study and only

193 provide basic pilot data. The study could be underpowered to find statistically significant

194 associations. A larger study that evaluated students over a semester of lectures and evaluated

195 electronic activity without seeking accurate self reporting is needed to confirm results. Another

196 limitation is that students answered the post-lecture test and then, immediately, answer the post- 
197 lecture survey which requires them to self report activities related to electronic activities. This

198 may result in biased answers as students realize the purpose of the surveys. The regression

199 models in the current study explained only a small proportion of variance in test scores. This

200 clearly shows that there could be a multitude of other variables apart from gender and distractions

201 which could influence test scores. Consequently, the issue of omitted variables bias should not be 202 discounted. Finally, this is a small, single site study and information may not be generalizable. 


\section{CONCLUSIONS}

204 Sixty five percent of students in a traditional lecture reported being distracted by email, Facebook

205 or text messages. Those who were distracted during the lecture performed similarly in the post-

206 lecture test to the undistracted group. However, results should be interpreted with caution as this

207 study was a small quasi-experimental design and further research should examine the influence of 208 different types of distraction on different types of learning. 
210 Blue CM. Do dental hygiene students fit the learning profile of the millennial student? J Dent

211 Educ. 2009;73(12):1372-8.

212 Elam C, Stratton T, Gibson DD. Welcoming a new generation to college: the millennial

213 students. J Col Admis. 2007;Spring(195):20-5.

214 Farley J, Risko EF, Kingstone A. Everyday attention and lecture retention: the effects of time,

215 fidgeting, and mind wandering. Front Psychol. 2013 Sep 18;4:619.

216 Huffington Post website. Accessed 2/15/14 and available at

217 http://www.huffingtonpost.com/2013/10/29/women-better-than-men-multitasking-study-

218 finds_n_4175470.html

219 Karpicke JD, Blunt JR. Retrieval practice produces more learning than elaborative studying

220 with concept mapping. Science. 2011 Feb 11;331(6018):772-5.

221 Live Science website. Accessed 2/15/14 and available at http://www.livescience.com/40740-

222 women-better-at-multitasking.html

223 Mäntylä T. Gender differences in multitasking reflect spatial ability. Psychol Sci. 2013

224 Apr;24(4):514-20.

225 Massachusetts Institute of Technology website. Accessed 2/4/14 and available at

226 http://ocw.mit.edu/about/

227 National Geographic website. Accessed 2/12/14 and available at

228 http://news.nationalgeographic.com/news/2013/13/131101-multitasking-women-productivity-

229 psychology/

230 Pew Internet and American Life Project. Generations 2010. Washington, DC: Pew Research 231 Center;2010.29 p. 
232 Pew website -a . Accessed at $6 \mathrm{pm}$ on 5/7/2014 and available at

233 http://www.pewinternet.org/2012/11/01/how-teens-do-research-in-the-digital-world/

234 Pew website -b. Accessed 6.10pm on 5/7/2014 and available at

235 http://www.pewsocialtrends.org/2010/02/24/millennials-confident-connected-open-to-

236 change/.

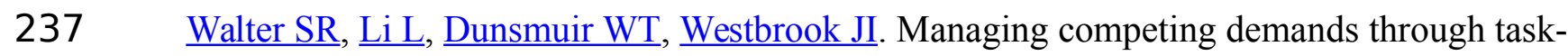

238 switching and multitasking: a multi-setting observational study of 200 clinicians over 1000

239 hours. BMJ Qual Saf. 2013 Oct 17. 


\section{Table $\mathbf{1}_{\text {(on next page) }}$}

Table 1

Distribution of Scores (Scale of 0 to 12) 
Table 1. Distribution of Scores (Scale of 0 to 12)

\begin{tabular}{|c|c|c|c|c|}
\hline Measure & All Students & $\begin{array}{c}\text { Students that } \\
\text { were } \\
\text { distracted } \\
(\mathrm{N}=17)\end{array}$ & $\begin{array}{l}\text { Students that } \\
\text { were not } \\
\text { distracted ( } \mathrm{N} \\
=9 \text { ) }\end{array}$ & p-value* \\
\hline Mean & 9.85 & 9.53 & 10.44 & \multirow[t]{7}{*}{0.652} \\
\hline $\begin{array}{l}\text { Standard } \\
\text { deviation }\end{array}$ & 2.89 & 3.20 & 2.24 & \\
\hline Minimum & 4 & 4 & 6 & \\
\hline $25^{\text {th }}$ percentile & 7.75 & 6 & 8.50 & \\
\hline Median & 12 & 12 & 12 & \\
\hline $75^{\text {th }}$ percentile & 12 & 12 & 12 & \\
\hline Maximum & 12 & 12 & 12 & \\
\hline
\end{tabular}

Man Whitney $\mathrm{U}$ test was used to compare distribution of scores between distracted and non-distracted students 


\section{Table 2 (on next page)}

Table 2

. Multivariable Linear Regression Analysis for Examining the Effects of Gender and Distraction on Test Scores 
Table 2. Multivariable Linear Regression Analysis for Examining the Effects of Gender and Distraction on Test Scores

\begin{tabular}{|c|c|c|}
\hline Independent Variable & $\begin{array}{c}\text { Parameter Estimate } \\
(95 \% \mathrm{Cl})\end{array}$ & p-value \\
\hline $\begin{array}{c}\text { Gender } \\
\text { Male } \\
\text { Female }\end{array}$ & $\begin{array}{c}2.60(-0.02-5.21) \\
\text { Reference }\end{array}$ & 0.052 \\
\hline $\begin{array}{c}\text { Distracted } \\
\text { Yes } \\
\text { No }\end{array}$ & $\begin{array}{c}0.07(-2.47-2.61) \\
\text { Reference }\end{array}$ & 0.955 \\
\hline
\end{tabular}




\section{Table 3 (on next page)}

Table 3

Multivariable Linear Regression Analysis for Examining the Effects of Gender and Different types of Distractions on Test Scores 
Table 3. Multivariable Linear Regression Analysis for Examining the Effects of Gender and Different types of Distractions on Test Scores

\begin{tabular}{|l|c|c|}
\hline \multicolumn{1}{|c|}{ Independent Variable } & $\begin{array}{c}\text { Parameter Estimate } \\
\mathbf{( 9 5} \mathbf{~ C l})\end{array}$ & p-value \\
\hline $\begin{array}{c}\text { Gender } \\
\text { Male } \\
\text { Female }\end{array}$ & $\begin{array}{c}2.44(-0.23-5.10) \\
\text { Reference }\end{array}$ & 0.07 \\
\hline $\begin{array}{c}\text { Distracted by Checking } \\
\text { Email } \\
\text { Yes } \\
\text { No }\end{array}$ & $\begin{array}{c}-0.88(-3.39-1.64) \\
\text { Reference }\end{array}$ & 0.476 \\
\hline $\begin{array}{c}\text { Distracted by Sending } \\
\text { Email Yes } \\
\text { Yos }\end{array}$ & $\begin{array}{c}2.40(-1.08-5.87) \\
\text { Reference }\end{array}$ & 0.166 \\
\hline $\begin{array}{l}\text { Distracted by Checking } \\
\text { Facebook } \\
\text { Yes } \\
\text { No }\end{array}$ & $\begin{array}{c}-2.16(-6.32-2.01) \\
\text { Reference }\end{array}$ & 0.293 \\
\hline $\begin{array}{c}\text { Distracted by Sending } \\
\text { Text } \\
\text { Yes } \\
\text { No }\end{array}$ & $\begin{array}{c}3.66(-2.08-9.39) \\
\text { Reference }\end{array}$ & 0.199 \\
\hline
\end{tabular}

